\title{
Resposta de Plantas de Beterraba (Beta vulgaris) e de Cenoura (Daucus carota) À Deriva Simulada de Glyphosate e Clomazone ${ }^{1}$
}

\author{
Response of Beetroot (Beta vulgaris) and Carrot (Daucus carota) to Simulated Glyphosate \\ and Clomazone Drift
}

RIGOLI, R.P. ${ }^{2}$, FONTANA, L.C. ${ }^{3}$, FIGUEREDO, S.S. ${ }^{3}$ e NOLDIN, J.A. ${ }^{4}$

\begin{abstract}
RESUMO - Várias espécies de hortaliças são de muita importância para a alimentação humana e tornam-se alvos da deriva de herbicidas, pois comumente são cultivadas nas proximidades de culturas como arroz, soja e milho, pulverizadas com esses produtos. Neste trabalho, objetivou-se verificar possiveis efeitos de doses reduzidas dos herbicidas glyphosate e clomazone sobre plantas de beterraba (Beta vulgaris) e de cenoura (Daucus carota), em diferentes fases de desenvolvimento. As doses avaliadas dos herbicidas foram de $0,5,10,15$ e $20 \%$ da dose recomendada, equivalentes a $0,63,126,189$ e $252 \mathrm{~g}^{\text {ha }}{ }^{-1}$ de glyphosate e $0,14,4,28,8,43,2$ e $57,6 \mathrm{~g} \mathrm{ha}^{-1}$ de clomazone, respectivamente, aplicadas aos 20, 30 e 40 dias após a emergência das culturas. Observou-se aumento no percentual de fitotoxicidade do glyphosate com o incremento na dose do herbicida, e a maior suscetibilidade ocorreu com a deriva nos estádios mais precoces, em ambas as espécies. As doses de clomazone não causaram qualquer sintoma detectável visualmente para as plantas de beterraba e de cenoura. Os resultados sugerem que o herbicida glyphosate causa injúrias às plantas de beterraba e cenoura, independentemente do estádio em que ocorre a interceptação do produto. No entanto, o herbicida clomazone não interfere no desenvolvimento inicial de plantas de beterraba e cenoura.
\end{abstract}

Palavras-chave: herbicida, fitotoxicidade, hortaliças.

\begin{abstract}
Herbicide drift over horticultural crops is a common problem in the state of Rio Grande do Sul, mainly in areas near rice, soybean and corn fields. The objective of this research was to evaluate glyphosate and clomazone drift effects on beetroot (Beta vulgaris) and carrot (Daucus carota) plants. The herbicides were sprayed at three different growth stages: 20, 30 and 40 days after seedling emergence. Herbicide rates evaluated were $0,5,10,15$, and $20 \%$ of the label rate. The sprayed rates were 0,63, 126, 189 and $252 \mathrm{~g} \mathrm{ha-1}$ of glyphosate and 0.0, 14.4, $28.8,43.2$ and $57.6 \mathrm{~g} \mathrm{ha}^{-1}$ of clomazone. Glyphosate injury to beetroot and carrot increased with herbicide rate, with the highest injury being observed at the earlier growth stage. Clomazone did not injure beetroot and carrot plants at any tested rate or growth stage. The results of this study suggest that glyphosate drift damages beetroot and carrot at any growth stage. However, beetroot and carrot are not sensitive to clomazone drift.
\end{abstract}

Keywords: herbicide, crop injury, vegetables.

1 Recebido para publicação em 19.7.2007 e na forma revisada em 31.3.2008.

2 Bióloga, Mestranda do Programa de Pós-Graduação em Fitossanidade, FAEM/UFPel, Caixa Postal 354, 95015-560, PelotasRS, <rubiapiesanti@yahoo.com.br>; ${ }^{3}$ Eng $^{\mathrm{a}}-$ Agr ${ }^{\mathrm{a}}$., Mestranda do Programa de Pós-Graduação em Fitossanidade, FAEM/UFPel; ${ }^{4}$ Engo-Agr ${ }^{0}$., Ph.D., Pesquisador da Epagri/Estação Experimental de Itajaí, Caixa Postal 277, 88301-970, Itajaí-SC, $<$ noldin@epagri.sc.gov.br>. 


\section{INTRODUÇÃO}

O Rio Grande do Sul é um Estado com grande produção agrícola, com destaque para as culturas de arroz irrigado, soja e milho, que demandam a aplicação de grande volume de agrotóxicos, incluindo herbicidas. Há também a produção de hortaliças em escala comercial, e entre as espécies comumente cultivadas estão a beterraba (Beta vulgaris), pertencente à família Chenopodiaceae, e a cenoura (Daucus carota), pertencente à família Apiaceae. Muitas das áreas de produção de hortaliças estão localizadas nas proximidades de grandes lavouras, onde a utilização de herbicidas pode afetar as culturas não-alvo por meio da deriva.

A deriva ocorre devido ao arraste de pequenas gotas, da calda herbicida pulverizada, pelo vento ou pela volatilização do produto. Entre os fatores que interferem na ocorrência da deriva podem ser mencionados: características do herbicida, tipo de equipamento, calibração, tipo de pontas de pulverização, técnicas de aplicação, condições meteorológicas e habilidade do operador (Costa et al., 2007; Cunha et al., 2003; Ozkan, 2000; Penckowski et al., 2003; Viana et al., 2007).

O dano causado por deriva de herbicidas é reconhecido como um problema em muitas áreas (Hemphill Jr. \& Montgomery, 1981); a sua detecção tem grande importância, pois, enquanto as perdas ocasionadas por esse fator não forem facilmente identificadas, produtores de plantas sensiveis em áreas adjacentes podem ter substanciais reduções na produção sem identificar a verdadeira causa (Schroeder et al., 1983). O grau de injúria e os sintomas observados são afetados por fatores como a espécie, o estádio de desenvolvimento da planta, o clima, o mecanismo de ação e a dose do herbicida (Al-Khatib et al., 2003).

Os herbicidas glyphosate e clomazone destacam-se dentre os mais comumente utilizados em grandes culturas no Rio Grande do Sul. O glyphosate pertence ao grupo químico das glicinas substituídas, classificado como não-seletivo e de ação sistêmica com amplo espectro de ação para espécies daninhas. É predominantemente absorvido pela região clorofilada das plantas (folhas e tecidos verdes) e translocado principalmente pelo floema para os tecidos meristemáticos (Rodrigues \& Almeida, 2005; Trezzi et al., 2001). O clomazone pertence ao grupo químico das isoxazolidinonas, grupo este que inibe a biossintese de carotenóides. É absorvido pelo meristema apical da planta, e uma vez que sua translocação ocorre pelo xilema (floema), seguindo o fluxo transpiracional, os sintomas de injúrias se manifestam nos órgãos mais novos (Rodrigues \& Almeida, 2005).

O desenvolvimento de várias culturas produtoras de alimentos, incluindo as espécies hortícolas, pode ser afetado tanto qualitativa como quantitativamente quando expostas a subdoses de herbicidas. Nesse sentido, Gilreath et al. (2000) observaram interação significativa entre doses de glyphosate e estádios de desenvolvimento das plantas de pimentão. Os efeitos negativos de doses reduzidas do herbicida glyphosate também foram observados em plantas de milho, soja, sorgo, algodão, tomate e eucalipto, com ocorrência de intoxicação e redução de crescimento e produtividade (Alves et al., 2000; Ellis \& Griffin, 2002; Figueredo, 2006; Magalhães et al., 2001a, b; Tuffi Santos et al., 2006; Yamashita \& Guimarães, 2005, 2006).

Efeitos negativos da deriva simulada do herbicida clomazone foram observados sobre tomateiro e laranjeira (Figueredo, 2006; Timossi $\&$ Alves, 2001). Para a cultura da beterraba em diferentes estádios de desenvolvimento, doses reduzidas dos herbicidas dicamba, 2,4-D e picloram provocaram intoxicação, que resultou em redução na produtividade e na qualidade do produto colhido (Schroeder et al., 1983).

A ocorrência de deriva dos herbicidas glyphosate e clomazone pode causar danos nas culturas da beterraba e cenoura, e a injúria ocasionada pode variar em função da época em que ocorre a interceptação dos herbicidas. Assim, objetivou-se neste trabalho verificar a resposta de plantas de beterraba e cenoura, em três estádios de desenvolvimento, quando submetidas a doses reduzidas dos herbicidas glyphosate e clomazone.

\section{MATERIAL E MÉTODOS}

Foram realizados quatro experimentos em casa de vegetação da Faculdade de Agronomia 
Eliseu Maciel, da Universidade Federal de Pelotas (UFPel), localizada no município de Capão do Leão, RS, no periodo de maio a julho de 2006.

O primeiro e o segundo experimento foram realizados para determinar o efeito dos herbicidas glyphosate e clomazone em plantas de beterraba; e o terceiro e o quarto, para avaliar o efeito dos mesmos herbicidas em plantas de cenoura.

As unidades experimentais constaram de recipientes de poliestireno, preenchidos com $2,5 \mathrm{~kg}$ de solo peneirado, classificado como Argissolo Vermelho-Amarelo distrófico, pertencente à Unidade de Mapeamento Camaquã (Embrapa, 1999). Em cada recipiente foram semeadas quatro sementes de beterraba ou de cenoura; após a emergência das plântulas, procedeu-se ao desbaste, selecionando somente uma planta por recipiente. Para a cultura da beterraba foi utilizado o cultivar Maravilha, e para a cenoura, o cultivar Nantes.

A adubação foi realizada conforme as recomendações para a cultura, e a irrigação, efetuada diariamente, de acordo com a necessidade das plantas.

Em todos os experimentos, o delineamento experimental utilizado foi de blocos casualizados, com quatro repetições. Os tratamentos foram arranjados em esquema fatorial, em que o fator A constou de épocas de aplicação do herbicida glyphosate ou clomazone $(20,30$ ou 40 DAE - dias após a emergência das culturas) e o fator B constou de doses dos herbicidas simulando deriva, correspondentes a 0 (testemunha sem aplicação), 5, 10, 15 e 20\% da dose recomendada, equivalentes a $0,63,126,189$ e $252 \mathrm{~g} \mathrm{ha}^{-1}$ de glyphosate ou $0,14,4,28,8,43,2$ e $57,6 \mathrm{~g}$ i.a. ha $\mathrm{ha}^{-1}$ de clomazone, respectivamente. A formulação de glyphosate utilizada foi a Roundup Original ${ }^{\circledR}\left(360\right.$ g L $\left.^{-1}\right)$, e de clomazone, o produto comercial Gamit $360 \mathrm{CS}^{\circledR}\left(360 \mathrm{~g} \mathrm{~L}^{-1}\right)$.

A aplicação foi efetuada com auxílio de um pulverizador costal pressurizado a $\mathrm{CO}_{2}$, munido com ponta tipo leque 110.02 , regulado com pressão de $210 \mathrm{kPa}$, calibrado para um volume de calda de $150 \mathrm{~L} \mathrm{ha}^{-1}$ de calda herbicida. No momento da aplicação, aos 20, 30 e 40 dias após a emergência (DAE), as plantas de beterraba encontravam-se com três, seis e nove folhas, e as plantas de cenoura, com duas, quatro e seis folhas, respectivamente.
As variáveis analisadas foram intoxicação e massa seca das plantas. A intoxicação das culturas foi observada visualmente aos 7,14 e 21 dias após aplicação dos tratamentos (DAT), utilizando a escala percentual de zero a cem 100, em que zero representava ausência de sintomas e 100, a morte da planta. Aos 21 DAT, as plantas foram coletadas (parte aérea e sistema radical) e secas em estufa com circulação de ar a $65 \pm 3{ }^{\circ} \mathrm{C}$, para determinação da massa seca $(\mathrm{g})$.

Os dados obtidos foram avaliados quanto à sua homocedasticidade e, posteriormente, submetidos à análise da variância $(\mathrm{p} \leq 0,05)$; sendo esta significativa, os efeitos do fator dose foram analisados por modelos de regressão linear e não-linear.

\section{RESULTADOS E DISCUSSÃO}

A aplicação de subdoses do herbicida glyphosate resultou em danos acentuados às plantas de beterraba nos três estádios de desenvolvimento. Para intoxicação, houve interação entre época de aplicação e doses do herbicida (Figura 1). A intoxicação foi mais acentuada quando o herbicida glyphosate foi aplicado nos estádios mais precoces das plantas de beterraba. Nas aplicações aos 20 e 30 DAE, observou-se que doses a partir de $126 \mathrm{~g} \mathrm{ha}^{-1}$ de glyphosate resultaram na morte de todas as plantas de beterraba, aos 14 DAT. Já na aplicação deste herbicida aos $40 \mathrm{DAE}$, a morte das plantas foi observada aos 21 DAT. Outros trabalhos também evidenciaram que plantas mais jovens de beterraba foram mais sensiveis à deriva de 2,4-D (Schroeder et al., 1983), e plantas de tomateiro (Figueredo, 2006) e pimentão (Gilreath et al., 2000) apresentaram maiores injúrias por glyphosate quando este foi aplicado na fase inicial de desenvolvimento.

Os dados de porcentagem de intoxicação das plantas de beterraba causada pelo glyphosate ajustaram-se adequadamente ao modelo exponencial em todas as épocas de aplicação e avaliação (Figura 1). A porcentagem de injúria aumentou com o incremento da dose do produto, em todos os períodos de avaliação; a partir dos 14 DAT foram evidenciados sintomas de intoxicação próximos a $100 \%$. Inicialmente, observou-se paralisação no crescimento das plantas de beterraba, seguida por murcha. Nas

Planta Daninha, Viçosa-MG, v. 26, n. 2, p. 451-456, 2008 
avaliações subseqüentes foi constatada clorose, seguida de necrose e morte das plantas, concordando com o quadro sintomatológico referente a esse herbicida, relatado por Trezzi et al. (2001). Sintomatologia similar também foi observada por Russo (1990), o qual relatou que plantas de tomateiro expostas a doses reduzidas de glyphosate apresentaram clorose nas folhas jovens e no ápice da haste principal. O glyphosate, sendo considerado um herbicida não-seletivo, quando utilizado em doses reduzidas crescentes, promove aumento progressivo na injúria foliar, reduzindo o vigor das plantas e, conseqüentemente, a produtividade de pimentão (Gilreath et al., 2000).

Para a variável massa seca, embora tenha havido interação entre os fatores época e doses do herbicida, a diferença entre as épocas de aplicação não foi considerada, pois essa comparação seria incoerente, visto que a aplicação do glyphosate foi feita em três fases distintas da cultura (Figura 2). Os dados ajustaram-se adequadamente à equação exponencial; a produção de massa seca das plantas de beterraba foi reduzida com o aumento nas doses do herbicida glyphosate, independentemente da época de aplicação.



Figura 1 - Intoxicação do herbicida glyphosate sobre plantas de beterraba, cv. Maravilha, em aplicações realizadas aos $20(\bullet), 30(\mathbf{o})$ e $40(\boldsymbol{\nabla})$ dias após a emergência. FAEM/ UFPel, Capão do Leão/RS, 2006. (DAT: dias após o tratamento)
Plantas de beterraba tratadas com o herbicida clomazone não mostraram nenhum sintoma visual de injúria, independentemente da dose do herbicida ou estádio das plantas no momento da aplicação. A produção de massa seca também não foi afetada pelas doses ou épocas de aplicação de clomazone (dados não apresentados). Isso pode ter decorrido das condições climáticas favoráveis ao crescimento e desenvolvimento das plantas e/ou metabolização do herbicida a compostos não-tóxicos e também devido ao fato de esse herbicida ter ação em pré-emergência ou pós-inicial sobre as plantas (Rodrigues \& Almeida, 2005).

Quanto à cultura da cenoura, a aplicação do herbicida glyphosate (terceiro experimento) foi prejudicial às plantas e a intoxicação variou de acordo com a época de aplicação e com a dose do herbicida. Comparando as épocas de aplicação, observou-se que nos estádios mais precoces as plantas de cenoura apresentaram maior porcentagem de injúria pelo glyphosate (Figura 3), similarmente ao observado para beterraba.

O efeito da deriva de glyphosate nos estádios iniciais de desenvolvimento das plantas é mais prejudicial do que nos estádios mais avançados, independentemente da espécie, e pode ocasionar perdas na produtividade (Magalhães et al., 2001a, b).

A resposta de intoxicação ocasionada em plantas de cenoura pelo herbicida glyphosate ajustou-se adequadamente aos modelos de equação exponencial (20 DAE) e linear (30 e 40 DAE) em todas as avaliações (Figura 3). Observou-se aumento do percentual de injúria

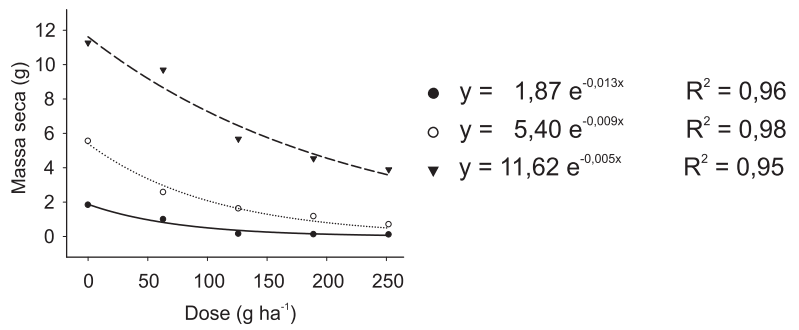

Figura 2 - Massa seca acumulada de plantas de beterraba, cv. Maravilha, em função de aplicações de subdoses do herbicida glyphosate realizadas aos $20(\bullet), 30(\mathbf{o})$ e $40(\boldsymbol{\nabla})$ dias após a emergência, avaliada aos 21 dias após o tratamento. FAEM/ UFPel, Capão do Leão/RS, 2006. 


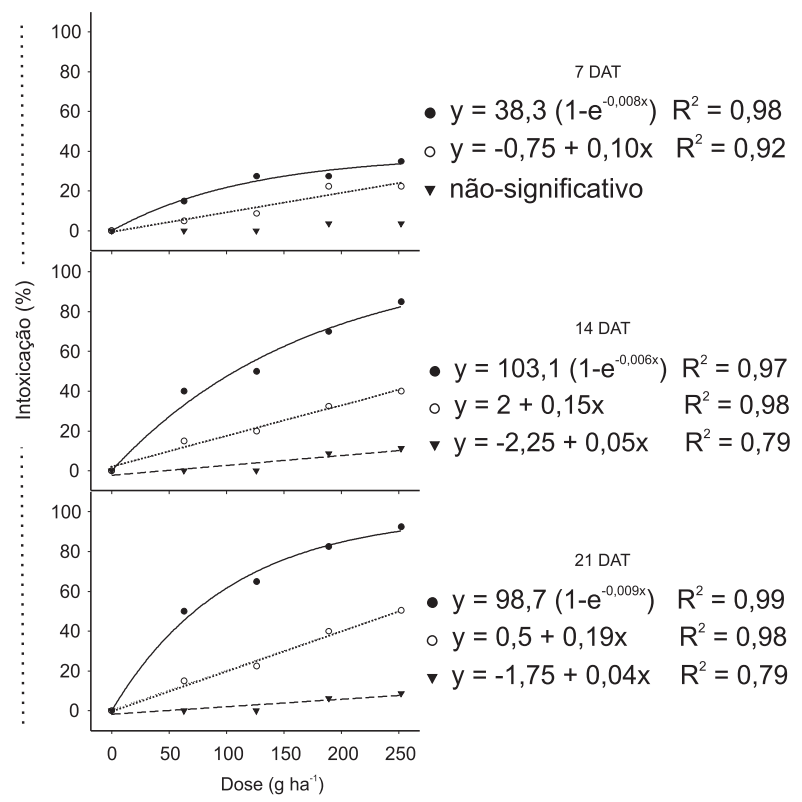

Figura 3 - Intoxicação do herbicida glyphosate sobre plantas de cenoura, cv. Nantes, nas aplicações realizadas aos 20 $(\bullet), 30(\mathbf{o})$ e 40 ( $\boldsymbol{\nabla})$ dias após a emergência. FAEM/UFPel, Capão do Leão/RS, 2006. (DAT: dias após o tratamento).

com o incremento na dose do produto. Os sintomas observados estão de acordo com a sintomatologia descrita por Trezzi et al. (2001).

O acúmulo de massa seca das plantas de cenoura foi prejudicado com a aplicação de glyphosate (Figura 4). A comparação entre as épocas de aplicação não foi realizada, visto que a diferença existente é oriunda do tamanho da planta no momento da aplicação, que foi realizada em três fases distintas da cultura. Não houve interação significativa entre época de aplicação e dose do herbicida; dessa forma, a resposta da cultura variou apenas com a dose do herbicida. Os dados ajustaram-se à equação linear, e a produção de massa seca foi reduzida com o incremento na dose do herbicida.

A aplicação de doses reduzidas do herbicida clomazone não ocasionou danos na cultura da cenoura (quarto experimento). Os efeitos fitotóxicos não foram significativos e a produção de massa seca não foi prejudicada. Resultados semelhantes foram obtidos por Figueredo (2006) com aplicação de até $194 \mathrm{~g} \mathrm{ha}^{-1}$ de clomazone sobre plantas de tomate. Já Timossi \& Alves (2001) observaram que é necessária dose mais elevada desse herbicida (1.000 $\left.\mathrm{g} \mathrm{ha}^{-1}\right)$ para

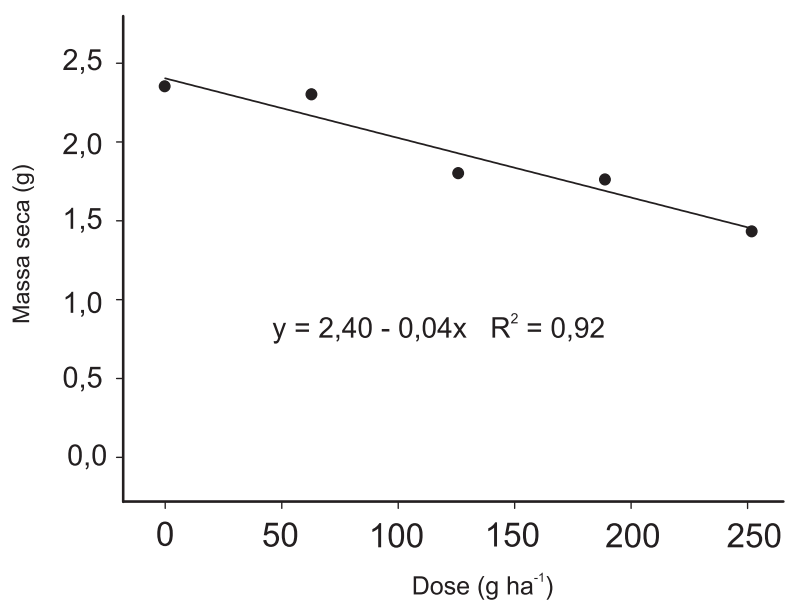

Figura 4 - Massa seca acumulada de plantas de cenoura, cv. Nantes, em função de aplicações de subdoses do herbicida glyphosate, avaliada aos 21 dias após tratamento. FAEM/ UFPel, Capão do Leão/RS, 2006

ocasionar manchas cloróticas e morte de ramos de laranjeira.

Doses reduzidas do herbicida glyphosate interferem negativamente nas culturas da beterraba e da cenoura, com danos mais intensos quando o herbicida é interceptado por plantas mais jovens, aos 20 dias após a emergência. A deriva do herbicida clomazone, até a dose de $58 \mathrm{~g} \mathrm{ha}^{-1}$, não é prejudicial às plantas de cenoura e beterraba.

\section{LITERATURA CITADA}

AL-KHATIB, K. et al. Grain sorghum response to simulated drift from glufosinate, glyphosate, imazethapyr and sethoxydim. Weed Technol., v. 17, n. 2, p. 261-265, 2003.

ALVES, L. W. R. et al. Efeito da aplicação de subdoses dos herbicidas glyphosate e oxyfluorfen, simulando deriva sobre a cultura do milho (Zea mays L.). Ci. Agrotec., v. 24, n. 4, p. $889-897,2000$.

COSTA, A. G. F. et al. Efeito da intensidade do vento, da pressão e de pontas de pulverização na deriva de aplicações de herbicidas em pré-emergência. Planta Daninha, v. 25, n. 1, p. 203-210, 2007.

CUNHA, J. P. A. R. et al. Avaliação de estratégias para redução da deriva de agrotóxicos em pulverizações hidráulicas. Planta Daninha, v. 21, n. 2, p. 325-332, 2003.

ELLIS, J. M.; GRIFFIN, J. L. Soybean (Glycine max) and cotton (Gossypium hirsutum) response to simulated drift of glyphosate and glufosinate. Weed Technol., v. 16, n. 3, p. $580-586,2002$. 
EMPRESA BRASILEIRA DE PESQUISA

AGROPECUÁRIA - EMBRAPA. Centro Nacional de Pesquisa de Solos. Sistema brasileiro de classificação de solos. Rio de Janeiro: 1999. 412 p.

FIGUEREDO, S. S. Efeitos de doses reduzidas dos herbicidas glyphosate e clomazone sobre a cultura do tomateiro (Lycopersicon esculentum). 2006. $60 \mathrm{f}$.

Dissertação (Mestrado em Fitossanidade) - Universidade Federal de Pelotas, Pelotas, 2006.

GILREATH, J. P.; CHASE, C. A.; LOCASCIO, S. J Phytotoxic effects of glyphosate on pepper (Capsicum annuит). Weed Technol., v. 14, n. 3, p. 488-494, 2000

HEMPHILL Jr., D. D.; MONTGOMERY, M. L. Response of vegetable crops to sublethal application of 2,4-D. Weed Sci., v. 29, p. 632-635, 1981.

MAGALHÃES, P. C. et al. Efeito de doses reduzidas de glyphosate e paraquat simulando deriva na cultura do milho. Planta Daninha, v. 19, n. 2, p. 247-253, 2001a.

MAGALHÃES, P. C. et al. Efeito de doses reduzidas de glyphosate e paraquat simulando deriva na cultura do sorgo. Planta Daninha, v. 19, n. 2, p. 255-262, 2001b.

OZKAN, H. E. Reducing spray drift, 2000. Disponível em $<$ http://ohioline.osu.edu/b816/index.html > Acesso em: $10 \mathrm{de}$ maio de 2007.

PENCKOWSKI, L. H.; PODOLAN, M. J.; LÓPEZOVEJERO, R. F. Influência das condições climáticas no momento da aplicação de herbicidas pós-emergentes sobre a eficácia de controle de nabiça (Raphanus raphanistrum) na cultura do trigo. Planta Daninha, v. 21, n. 3, p. 435-442, 2003.
RODRIGUES, B. N.; ALMEIDA, F. S. Guia de

herbicidas. Londrina: Edição dos autores, 2005. 592 p.

RUSSO, V. M. Reaction of tomato cultivars to a sublethal dose of glyphosate. Hortscience, v. 25, n. 12, p. 162, 1990.

SCHROEDER, G. L.; COLE, D. F.; DEXTER, A. G. Sugarbeet (Beta vulgaris L.) response to simulated herbicide spray drift. Weed Sci., v. 31, p. 831-836, 1983.

TIMOSSI, P. C.; ALVES, P. L. C. A. Efeitos da simulação de deriva de clomazone em plantas de laranjeira 'hamlin'

R. Bras. Frutic., v. 23, n. 2, p. 310-314, 2001.

TREZZI, M. M.; KRUSE, N. D.; VIDAL, R. A. Inibidores de EPSPS. In: VIDAL, R. A.; MEROTTO Jr., A.

Herbicidologia. Porto Alegre: Evangraf, 2001. p. 37-45.

TUFFI SANTOS, L. D. et al. Intoxicação de espécies de eucalipto submetidas à deriva do glyphosate. Planta

Daninha, v. 24, n. 2, p. 359-364, 2006.

VIANA, R. G. et al. Características técnicas de pontas de pulverização LA-1JC e SR-1. Planta Daninha, v. 25, n. 1, p. $211-218,2007$

YAMASHITA, O. M.; GUIMARÃES, S. C. Resposta de cultivares de algodoeiro a subdoses de glyphosate. Planta Daninha, v. 23, n. 4, p. 627-633, 2005.

YAMASHITA, O. M.; GUIMARÃES, S. C. Deriva simulada de glyphosate em algodoeiro: efeito de dose, cultivar e estádio de desenvolvimento. Planta Daninha, v. 24, n. 4, p. 821-826, 2006. 